\title{
High-Affinity CRF, Receptor Antagonist NBI-3404I: Preclinical and Clinical Data Suggest Safety and Efficacy in Attenuating Elevated Stress Response
}

\author{
Marcus Ising*,', Ulrich S Zimmermann',,4, Heike E Künzel ${ }^{1,5}$, Manfred Uhr', Alan C Foster², \\ Susan M Learned-Coughlin ${ }^{3}$, Florian Holsboer' and Dimitri E Grigoriadis*,2 \\ 'Max-Planck-Institute of Psychiatry, Munich, Germany; ${ }^{2}$ Neurocrine Biosciences Inc., San Diego, CA, USA; ${ }^{3}$ GlaxoSmithKline, Research Triangle \\ Park, NC, USA
}

\begin{abstract}
There is an extensive evidence that corticotropin releasing factor (CRF) is hypersecreted in depression and anxiety, and blockade of CRF could have therapeutic benefit. We report preclinical data and the results of a clinical Phase I study with the novel nonpeptide CRF, antagonist NBI-3404I/SB723620. Preclinical data conducted with different cell lines expressing human CRF receptors and in Wistar and Sprague-Dawley rats indicate that NBI-3404I is effective in reducing endocrine responses to pharmacological and behavioral challenge mediated by $C R F$, receptors. These specific properties and its well-documented safety profile enabled a clinical Phase I study with 24 healthy male subjects receiving NBI-3404I (10,50, or $100 \mathrm{mg}$ ) or placebo for 14 days. Regulation of the hypothalamic-pituitaryadrenocortical (HPA) axis was evaluated by intravenous stimulation with $100 \mu \mathrm{g}$ of human CRF. Psychosocial stress response was investigated with the Trier Social Stress Test (TSST). Treatment with NBI-3404I did not impair diurnal adrenocorticotropic hormone $(\mathrm{ACTH})$ and cortisol secretion or CRF evoked $\mathrm{ACTH}$ and cortisol responses but attenuated the neuroendocrine response to psychosocial stress. These results suggest that NBI-3404I is safe and does not impair basal regulation of the HPA system but improves resistance against psychosocial stress. NBI-3404I demonstrates that inhibition of the CRF system is a promising target for drug development against depression and anxiety disorders.
\end{abstract}

Neuropsychopharmacology (2007) 32, I941-1949; doi:I0.1038/sj.npp. I 301328; published online 7 February 2007

Keywords: corticotropin releasing factor; CRF, receptor antagonist; drug safety; psychosocial stress; anxiety; depression

\section{INTRODUCTION}

The ability to adapt to stress is required to avoid the development of a variety of diseases including anxiety and depression (de Kloet et al, 2005). In fact, abnormalities of the hypothalamic-pituitary-adrenocortical (HPA) axis, such as increased plasma cortisol levels at baseline or following challenge tests are the most consistent laboratory finding in depression. Moreover, normalization of this dysregulation precedes improvement in affective disorders

*Correspondence: Dr M Ising, Max-Planck-Institute of Psychiatry, Kraepelinstr. 2-10, 80804 Munich, Germany, Tel: + 498930622 430, Fax: + 498930622 544, E-mail: ising@mpipsykl.mpg.de and Dr DE Grigoriadis, 12790 El Camino Real, Neurocrine Biosciences Inc., San Diego, CA 92130, USA, Tel: + I 858617 767।, Fax: + 858 617 7830, E-mail: dgrigoriadis@neurocrine.com

${ }^{4}$ Current address: Department of Psychiatry and Psychotherapy, Universitätsklinikum Carl Gustav Carus, TU Dresden, Fetscherstrasze Str. 74, 0I307 Dresden, Germany.

${ }^{5}$ Current address: Klinikum Ingolstadt, Zentrum für Psychiatrie und Psychotherapie, Krumenauerstr. 25, 8502 I Ingolstadt, Germany.

Received 8 August 2006; revised 28 November 2006; accepted 13 December 2006 regardless of the type of treatment (Ising et al, 2005). Corticotropin releasing factor (CRF; also known as corticotropin releasing hormone, $\mathrm{CRH}$ ) is the primary mediator of the stress response and is released foremost from the paraventricular nucleus of the hypothalamus where it passes through the portal vasculature to act on specific receptors in the anterior pituitary to release adrenocorticotropic hormone (ACTH). The link between CRF and the manifestation of depressive symptomatology began with the observation that the cerebrospinal fluid (CSF) of depressed patients contained elevated levels of the CRF peptide (Nemeroff $e t a l, 1984$ ) and the demonstration that pituitary ACTH release following exogenous systemic administration of CRF was blunted among depressive patients (Gold et al, 1984; Holsboer et al, 1984a,b). This finding and the reported positive correlation observed between concentrations of CRF and the degree of dexamethasone induced plasma cortisol reduction (Roy et al, 1987) supported a key role for CRF in the neuroendocrine aspects of depression. In fact, the elevated levels of CRF in the CSF of depressed individuals was shown to be normalized following successful electroconvulsive therapy (Nemeroff et al, 1991). Furthermore, this evidence was strengthened by the 
findings in suicide victims where in post-mortem frontal cortical tissue, the CRF receptor-binding sites were significantly decreased, consistent with the mechanism of elevated levels of CRF in brain causing a homologous downregulation of CRF receptors (Merali et al, 2004; Nemeroff et al, 1988). Central administration of CRF as well as overexpression of CRF in transgenic mice resulted in behavioral changes including anxiety, disturbances of psychomotor activity, and sleep, anorexia, vegetative abnormalities, etc. (Britton et al, 1986; Pepin et al, 1992; Strohle et al, 1998), which are cardinal symptoms of depression. This evidence is consistent with the notion that CRF is hypersecreted in depression and that blockade of the CRF system, through specific and selective orally acting receptor antagonists could have a positive and therapeutic benefit in major depressive and anxiety related disorders. These results together with a plethora of other clinical and preclinical findings led to the formulation of the CRF hypothesis of depression (Holsboer, 2003).

CRF acts at two subtypes of G-protein coupled (GPCR) receptors that belong to the Class B family of GPCRs (Arzt and Holsboer, 2006). These receptors have been termed the $\mathrm{CRF}_{1}$ and the $\mathrm{CRF}_{2}$ receptor with the $\mathrm{CRF}_{2}$ receptor existing in three identified splice variant isoforms named $\mathrm{CRF}_{2(\mathrm{a})}$,

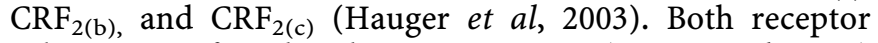
subtypes are found in human pituitary (Hiroi et al, 2001) and throughout the neocortex of primates (Sanchez et al, 1999), whereas in rodents only the $\mathrm{CRF}_{1}$ receptor is expressed in pituitary and neocortex, and has a discrete localization with respect to the $\mathrm{CRF}_{2}$ receptor (Chalmers et al, 1995). In addition to the neuropeptide CRF itself, there is a family of endogenous mammalian ligands described currently that activate these receptors called the urocortins. Urocortin 1 (UCN1) has equal affinity for both receptor subtypes although urocortin 2 and 3 (UCN2 and UCN3) have higher affinity and selectivity for the $\mathrm{CRF}_{2}$ receptor subtype (Perrin and Vale, 1999; Skelton et al, 2000). There have been many studies, detailing the role of this family of receptors and corresponding ligands in stress-related diseases including anxiety and depression, which has generated a tremendous amount of interest in the development of novel antagonists (Grigoriadis, 2005; Holsboer, 2003; Zorrilla and Koob, 2004).

The observations described above of increased levels of CRF during acute depression, and the fact that human CRF binds at the $\mathrm{CRF}_{1}$ receptor with 15 -fold higher affinity over the $\mathrm{CRF}_{2}$ receptor led to the hypothesis of selective $\mathrm{CRF}_{1}$ receptor antagonists as promising candidates for new antidepressants. Since 1991, a large number of small molecule $\mathrm{CRF}_{1}$ antagonists have been developed (McCarthy et al, 1999; Saunders and Williams, 2003; Zorrilla and Koob, 2004), with a small number entering clinical development. The first description of a clinically active $\mathrm{CRF}_{1}$ receptor antagonist appeared in the literature a few years ago and demonstrated a pharmacodynamic profile consistent with antidepressant activity (Held et al, 2004; Kunzel et al, 2003, 2005; Zobel et al, 2000). The development of this compound, however, was discontinued owing to moderate but reversible clinical safety concerns (temporarily elevated liver enzymes). We now report the pharmacokinetics and pharmacodynamics of a novel nonpeptide $\mathrm{CRF}_{1}$ antagonist, NBI-34041/SB723620 with improved physiochemical prop- erties to penetrate the central nervous system, which was achieved by reducing the overall lipophilicity compared with previous compounds (Gross et al, 2005). In addition to the in vitro and in vivo preclinical, and behavioral profile, this compound has been evaluated in a Phase I placebocontrolled dose escalation study in healthy male subjects where plasma ACTH and cortisol responses to exogenous administration of CRF and to psychosocial stress following subchronic treatment with escalating doses of this compound were measured.

\section{MATERIALS AND METHODS}

NBI-34041: 2-(2,4-dichlorophenyl)-4-methyl-6-(1-propylbutyl)-7,8-dihydro-6H-1,3,6,8a-tetraazaacenaphthylene, was synthesized at Neurocrine Biosciences Inc., and the full details of the synthesis have been described where the compound is designated 'compound 12t' (Gross et al, 2005).

\section{Preclinical In Vitro Measures}

Radioligand-binding studies. The ability of NBI-34041 to compete in membranes prepared from different cell lines expressing the human $\mathrm{CRF}_{1}$ or $\mathrm{CRF}_{2(\mathrm{a})}$ receptor was examined. The specific cell lines were chosen on the basis of the best expression level and signal-to-noise ratio in the assay with respect to each receptor subtype and used to determine the $K_{\mathrm{i}}$-value of the compound. In addition, NBI34041 was examined at the $\mathrm{CRF}_{2}$ receptor subtype in order to determine its subtype selectivity. $\left[{ }^{125} \mathrm{I}\right]$ Sauvagine was used to label both receptor subtypes because it has equal affinity for both the $\mathrm{CRF}_{1}$ and $\mathrm{CRF}_{2}$ receptors and standard radioligand binding assays were performed essentially as described previously (Grigoriadis et al, 1996).

Inhibition of cyclic AMP accumulation. The same cell lines expressing the human receptors were used to determine the functional activity of NBI 34041 as they respond to agonist in a receptor-specific manner with the stimulation of adenylate cyclase resulting in a measurable increase in cAMP. The inhibition of CRF- or sauvagine-stimulated cAMP by receptor antagonists is an indicator of the functional potency of those compounds. NBI-34041 was examined for its ability to block CRF or sauvaginestimulated cAMP accumulation in cells expressing the human $\mathrm{CRF}_{1}$ or $\mathrm{CRF}_{2}$ receptor. Using this set of data, both the functional potency and selectivity of NBI-34041 could be determined.

Inhibition of ACTH release. As in vitro animal models for the CRF system are typically performed in rats, the functional antagonist nature of NBI-34041 was examined using cultured rat anterior pituitary cells harvested from 7-week-old female Sprague-Dawley rats. A subset of cells from the anterior pituitary called corticotropes respond to the hormone CRF by synthesizing and releasing ACTH. The inhibition of ACTH by NBI-34041 further confirms the antagonist nature of this molecule and in addition identifies any differences in potency owing to possible species differences in the receptor sequence between the human and rat forms. 


\section{Preclinical In Vivo Measures}

For both CRF- and stress-induced ACTH release studies, male Wistar or Sprague-Dawley rats (300-350 g) were housed in groups of two where ambient temperature was $25-27^{\circ} \mathrm{C}$, and a $12-\mathrm{h}$ light/dark cycle was in effect $(0700 \mathrm{~h}-$ 1900 h). Rats were allowed food and water ad libitum. All protocols were approved by the Animal Care and Use Committee consistent with National Institutes of Health Guidelines.

Inhibition of CRF-induced ACTH release in rat. The ability of intragastric administration of NBI-34041 to inhibit the ACTH response to exogenously administered CRF was examined in the rat. Rats were anesthetized with isoflurane and implanted with a femoral vein catheter (IITC \#26A; PE 10 silastic) in the right groin area. The catheter was secured in place with 4-0 suture. A gastric catheter was placed in the stomach and sutured with a purse string suture (4-0 suture) to secure the cannula in place. The cannulae were fed subcutaneously to the dorsal section of the rat (behind the ears), where they exited and were sutured in place. All external incisions were closed using wound clips. These surgeries were performed three days before testing. Following baseline blood sampling in catheterized rats, NBI-34041 $(3,10$, or $30 \mathrm{mg} / \mathrm{kg})$ or vehicle $(2 \mathrm{ml} / \mathrm{kg})$ was infused through the intragastric tube, followed $60 \mathrm{~min}$ later by an i.v. injection of CRF $(0.3 \mathrm{nmol} / \mathrm{kg} ; 0.5 \mathrm{ml} / \mathrm{kg})$. There were six rats in each group. Blood was collected 2, 10, and $30 \mathrm{~min}$ after the CRF injection in EDTA tubes and the plasma stored at $-80^{\circ} \mathrm{C}$ until assessment of $\mathrm{ACTH}$ by radioimmunoassay (RIA) (ICN Biomedicals, Irvine, CA). Intragastric administration always preceded i.v. CRF administration by $60 \mathrm{~min}$. This time corresponds to the $T_{\max }$ for NBI 34041, which was determined to be $1.5 \mathrm{~h}$ by pharmacokinetic measures.

Inhibition of stress-induced $A C T H$ release in rat. The ability of NBI-34041 to inhibit the ACTH response from a stressor (intermittent footshock first described (Rossier et al, 1977)) was also examined. Rats were handled for 2 weeks to familiarize them with the apparatus and dosing paradigm to reduce the basal stress associated with those procedures. Animals (six per group) were dosed with vehicle or NBI-34041 (3, 10, and $30 \mathrm{mg} / \mathrm{kg}$ ) by oral gavage above $60 \mathrm{~min}$ before being placed in the operant boxes. Five minutes later, they were exposed to a series of mild intermittent footshocks for additional $10 \mathrm{~min}(1 \mathrm{ma}$ for $2 \mathrm{~s}$ every $15 \mathrm{~s}$ for a total of 33 shocks). They were transported in pairs to a procedure room and then anaesthetized under isoflurane for $1 \mathrm{~min}$; blood was collected and processed as described above for the determination of ACTH. A no treatment control group was left undisturbed in their home cages in the animal housing room until the time of the blood draw.

\section{Clinical Phase I Trial}

Subjects. Twenty-four healthy male volunteers without history of psychiatric disorders, verified by the Structural Clinical Interview for DSM-IV (SCID, German version (Wittchen et al, 1997)), were recruited for a 16 days in-house randomized double-blind placebo controlled dose escalation study with NBI-34041. Before study inclusion, all subjects were medically examined to rule out cardiovascular, endocrine, or metabolic disorders. Subjects were admitted to the study center before drug dosing (day 0 ) and remained at the study center 2 days after the final dose (day 16). After the in-house period, subjects reported for two follow-up examinations on day 20 and 30. Three study groups consisting of eight subjects each received NBI-34041 or placebo for 14 days. Six randomly selected subjects per group were treated daily with the active drug NBI-34041 in one of three doses $(10 ; 50 ; 100 \mathrm{mg} /$ day $)$. Two additional subjects of every study group received placebo for a total of six placebo subjects. All subjects finished the trial (no drop-out).

Human circadian neuroendocrine profile. Diurnal plasma ACTH and cortisol levels were measured on study days 1, 7, and 14 (0800, 0830, 0900, 1000, 1200, 1600, and $2000 \mathrm{~h}$ ); neuroendocrine profiles were evaluated as area under the curve (AUC) by trapezoidal integration. Samples were obtained via intravenous catheter, which was inserted $30 \mathrm{~min}$ before the first sample was collected.

Urinary free cortisol (UFC) was evaluated as $24 \mathrm{~h}$ concentration $(0730 \mathrm{~h}-0730 \mathrm{~h}$ the next day) on days 1,7 , and 14 .

CRF stimulation test. CRF stimulation tests were conducted on study days 0 (baseline) and 11. Plasma ACTH and cortisol responses were repetitively measured before and after administration of $100 \mu \mathrm{g}$ human CRF at $1500 \mathrm{~h}$ via i.v. catheter. Hormone responses to the hCRF injection were assessed as AUC by trapezoidal integration. The individual plasma ACTH and cortisol concentrations before the CRF injection (1445 and $1500 \mathrm{~h}$ ) served as baseline and were included as a covariate.

Trier social stress test. A standardized psychosocial stress test, the Trier Social Stress Test (TSST) (Kirschbaum et al, 1993; Zimmermann et al, 2004) was conducted in the afternoon of study day 9. The TSST is a public speaking task involving a mock job interview and mental arithmetic. After collection of baseline blood samples (via i.v. catheter) the subjects received a complete description of the mock job task. They were given $10 \mathrm{~min}$ to prepare a presentation for promoting their candidacy for a position that was tailored to their education. After the preparation time, subjects were escorted to another room to give their presentation in front of a panel of three judges evaluating the talk. After $5 \mathrm{~min}$, subjects were given an unexpected mental arithmetic task for a further 5 min. Both tasks, mock job presentation, and mental arithmetic, were videotaped to increase task engagement. Emotional response to the psychosocial stress test was retrospectively assessed with the state scale of the State-Trait-Anxiety Inventory (STAIX1, German version (Laux et al, 1981)). Blood samples for plasma ACTH and cortisol levels were repetitively collected before and after the public speaking. AUC values were calculated by trapezoidal integration. Prestress ACTH and cortisol concentrations served as baseline and were included as a covariate. 
Personality traits Neuroticism, Extraversion, and Psychoticism that may interfere with the psychosocial stress response were evaluated with the 50 items short version of the revised Eysenck Personality Questionnaire (EPQ-RK, German version (Ruch, 1999)).

The clinical trial was carried out at Parexel International Inc., Berlin (Germany) and was conducted in accordance with all applicable regulatory requirements, with 'good clinical practice', and with the guiding principles of the Declaration of Helsinki. Subjects gave written informed consent after all study details were explained. The study protocol was approved by the local ethical committee of the Landesaerztekammer Berlin (Berlin, Germany).

Neuroendocrine assessment. For plasma ACTH measurements an immunoradiometric assay without extraction (Nichols Institute, San Juan Capistrano, CA) was used. The detection limit for plasma ACTH was $4.0 \mathrm{pg} / \mathrm{ml}$, and the intra- and interassay coefficients of variation at $20 \mathrm{pg} / \mathrm{ml}$ plasma were $<8 \%$. For the determination of plasma and UFC a RIA kit (ICN Biomedicals, Irvine, CA) was used. The detection limit was $0.3 \mathrm{ng} / \mathrm{ml}$ plasma; intra- and interassay coefficients of variation for 20 and $40 \mathrm{ng} / \mathrm{ml}$ were $<7 \%$.

\section{Data Analysis}

For the in vitro experiments all data were analyzed using the iterative nonlinear least squares curve-fitting program 'Prism' (GraphPad Inc., San Diego, CA). For the radioligand binding experiments (determination of $K_{\mathrm{i}}$-values), the data were routinely fit to single and multiple binding site models compared statistically to determine whether a more complex data model was justified. For the inhibition of cAMP or ACTH studies, $\mathrm{IC}_{50}$ values for the inhibition of sauvagine-stimulated cAMP or CRF-stimulated ACTH were analyzed using the 'sigmoidal dose-response (variable slope)' option for curve fitting. Unknowns were calculated from the cAMP or ACTH standard curves performed simultaneously and under identical conditions (see supporting text for details).

For the rat preclinical in vivo measurements, ACTH values over time were analyzed using repeated measures, mixed design analysis of variance (ANOVA). Peak ACTH values were analyzed using one-way ANOVA, with Fischer's PLSD as the post hoc method of testing dose group differences.

For the clinical studies, multivariate analyses of variance were conducted with the four dose groups as independent factor. In case of a significant group effect, pair-wise post hoc tests were restricted to the comparison of the highest dose group and placebo (least square difference, LSD) in order to maintain the experiment-wise alpha level. For the evaluation of change during the treatment period (days 1, 7, and 14), a repeated measures factor was included, and Huynh-Feldt corrected p-values are reported. In case of a significant effect of the repeated measures factor, simple contrasts were applied comparing the results of day 1 with the results of the days 7 and 14. Group analysis for both functional assessments, that is, the CRF stimulation and the TSST, were conducted as MANCOVA controlling for the individual pre-CRF and prestress baseline values, respectively. All data were checked against the data protocols. The data set was almost complete. In two subjects, the results of the mental arithmetic task in the TSST were not available. One subject refused to participate in this task because of fear of failure. Another subject was obviously overstrained by the standard mental arithmetic, and an easier variant was conducted. SPSS 12.01 was applied for statistical data processing.

\section{RESULTS}

\section{Preclinical In Vitro Measures}

NBI-34041 (2-(2,4-dichlorophenyl)-4-methyl-6-(1-propylbutyl)-7,8-dihydro-6H-1,3,6,8a-tetraazaacenaphthylene) is a high affinity and selective $\mathrm{CRF}_{1}$ receptor neutral antagonist. In cells expressing the human $\mathrm{CRF}_{1}$ receptor, NBI-34041 could inhibit the binding of $\left[{ }^{125} \mathrm{I}\right]$ sauvagine in a concentration-dependent manner completely to baseline levels. Using the same cells expressing the human $\mathrm{CRF}_{2}$ receptor, NBI-34041 was unable to effectively compete for the binding of $\left[{ }^{125} \mathrm{I}\right]$ sauvagine with only a slight degree of inhibition observed at the highest concentration of $10 \mu \mathrm{M}$ tested. This demonstrates that NBI-34041 has high affinity and is selective for the $C^{2} F_{1}$ receptor although having almost no activity at the $\mathrm{CRF}_{2}$ receptor subtype. Table 1 shows the summary of a number of independent experiments used to determine the affinity of NBI-34041 (4.0 nM; mean $p K_{\mathrm{i}}=8.4 \pm 0.4, n=249$ ).

In order to determine whether NBI-34041 was a functional neutral antagonist, it was assessed for its ability to inhibit sauvagine-stimulated cAMP production from cells expressing the human $\mathrm{CRF}_{1}$ receptor. Sauvagine stimulates cAMP from cells expressing the human $\mathrm{CRF}_{1}$ receptor in a concentration-dependent manner with an approximate $\mathrm{EC}_{50}$ of $1 \mathrm{nM}$. When $1 \mathrm{nM}$ sauvagine was used to stimulate cAMP,

Table I In Vitro Profile of NBI-3404I/SB723620

\begin{tabular}{|c|c|}
\hline 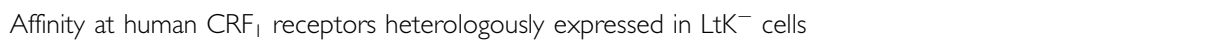 & $K_{i}=4.0 \mathrm{nM}(n=249)$ \\
\hline Inhibition of CRF-stimulated CAMP accumulation in $\mathrm{CHO}$ cells expressing the human CRF, receptor & $I C_{50}=58.9 n M(n=56)$ \\
\hline Inhibition of CRF-stimulated ACTH release in cultured rat anterior pituitary cells & $1 C_{50}=52.1 \mathrm{nM}(n=10)$ \\
\hline Affinity at human $\mathrm{CRF}_{2}$ receptors heterologously expressed in HEK-293 cells & $K_{i}>10000 \mathrm{nM}$ \\
\hline Inhibition of sauvagine stimulated cAMP accumulation in HEK-293 cells expressing the human $\mathrm{CRF}_{2}$ receptor & $I C_{50}>10000 \mathrm{nM}$ \\
\hline$T_{\max }$ in rat following administration by oral gavage $(3,10$, or $30 \mathrm{mg} / \mathrm{kg})$ & $1.5 \mathrm{~h}$ \\
\hline
\end{tabular}

Radioligand binding and cAMP accumulation studies were performed on the expressed human $\mathrm{CRF}_{1}$ or $\mathrm{CRF}_{2}$ receptors in $\mathrm{LtK}^{-}$, $\mathrm{HEK}-293$, or $\mathrm{CHO}$ cells. Inhibition of $\mathrm{ACTH}$ release was performed on primary cultures of rat anterior pituitary cells. 
NBI-34041 could inhibit the production of cAMP in a concentration-dependent manner with an $\mathrm{IC}_{50}$ of approximately $60 \mathrm{nM}\left(\mathrm{IIC}_{50}=7.2 \pm 0.3, n=56\right.$; see Table 1$)$. At concentrations of NBI-34041 up to $10000 \mathrm{nM}$, NBI-34041 was unable to fully inhibit sauvagine stimulated cAMP from cells expressing the human $\mathrm{CRF}_{2}$ receptor consistent with the binding studies and again confirming the functional selectivity of the compound for the $\mathrm{CRF}_{1}$ receptor. In addition, CRF-stimulated ACTH release assayed from cultured rat anterior pituitary cells was used to determine not only the functional antagonism but also to identify any species differences in the activity of this molecule between the cloned human receptor (used in the binding and cAMP studies) and the rat receptor. Table 1 demonstrates that when CRF was used to stimulate ACTH release from these cells, NBI-34041 inhibited this stimulation with an apparent $\mathrm{IC}_{50}$ of about $50 \mathrm{nM}\left(p \mathrm{IC}_{50}=7.3 \pm 0.3, n=10\right.$, see Table 1$)$ consistent with the cAMP findings and confirming the lack of species selectivity.

\section{Preclinical In Vivo Measures}

In preclinical in vivo studies, NBI-34041 significantly attenuated the elevation in plasma ACTH induced by i.v. administration of CRF (see Figure 1a). Repeated measures ANOVA on the total $30 \mathrm{~min}$ response revealed a significant interaction between dose group and time point $(\mathrm{F}(12,66)=5.4 ; p<0.0001)$. Post hoc analyses showed that when assessed over all time points tested, all doses significantly attenuated the increase in ACTH after CRF injection $(p<0.01-0.0001)$. For clarity, only the $10 \mathrm{~min}$ sampling time is shown in the figure, which corresponds to the peak ACTH levels achieved following i.v. CRF administration. ANOVA conducted on the full $30 \mathrm{~min}$ AUC showed that there was a significant treatment effect $(\mathrm{F}(4,22)=7.4 ; p<0.0006)$, with the 10 and $30 \mathrm{mg} / \mathrm{kg}$ doses giving significant attenuation of the CRF effect (76-82\%; $p<0.001-0.008$; data not shown). At the time of the peak ACTH response (10 min after CRF injection), all doses attenuated the CRF effect on ACTH $(45-84 \%$; $p<0.01-$ $0.0001)$. NBI-34041 also demonstrated efficacy in attenuating shock-induced ACTH release in a dose-dependent manner (Figure 2b). One way ANOVA revealed significant treatment effects $(\mathrm{F}(4,23)=12.9 ; p<0.0001)$, with a significant effect of stress $(p<0.0001 v s$ Veh/No Shock) and the $30 \mathrm{mg} / \mathrm{kg}$ dose as the MED for attenuation $(p<0.001 v \mathrm{seh} /$ Shock; $67 \%$ attenuation; see Figure $1 b$ ).

\section{Clinical Phase I Trial}

Twenty-four healthy male volunteers (mean age $=28 \pm 4$ years, range 20-35) participated in a 16-day randomized double-blind placebo controlled clinical study receiving NBI-34041 in one of three dosages (group 1: $10 \mathrm{mg} /$ day; group 2: $50 \mathrm{mg} /$ day; group 3: $100 \mathrm{mg} /$ day) or placebo for 2 weeks. The three active dose groups and the placebo group did not differ in age $(p=0.588)$ or in personality traits (neuroticism, extraversion, or psychoticism, $p=0.677$ ).

Circadian neuroendocrine profile. Diurnal plasma ACTH and cortisol secretion was monitored for $12 \mathrm{~h}(0800-2000 \mathrm{~h})$ at day 1,7 , and 14 . We did not observe significant
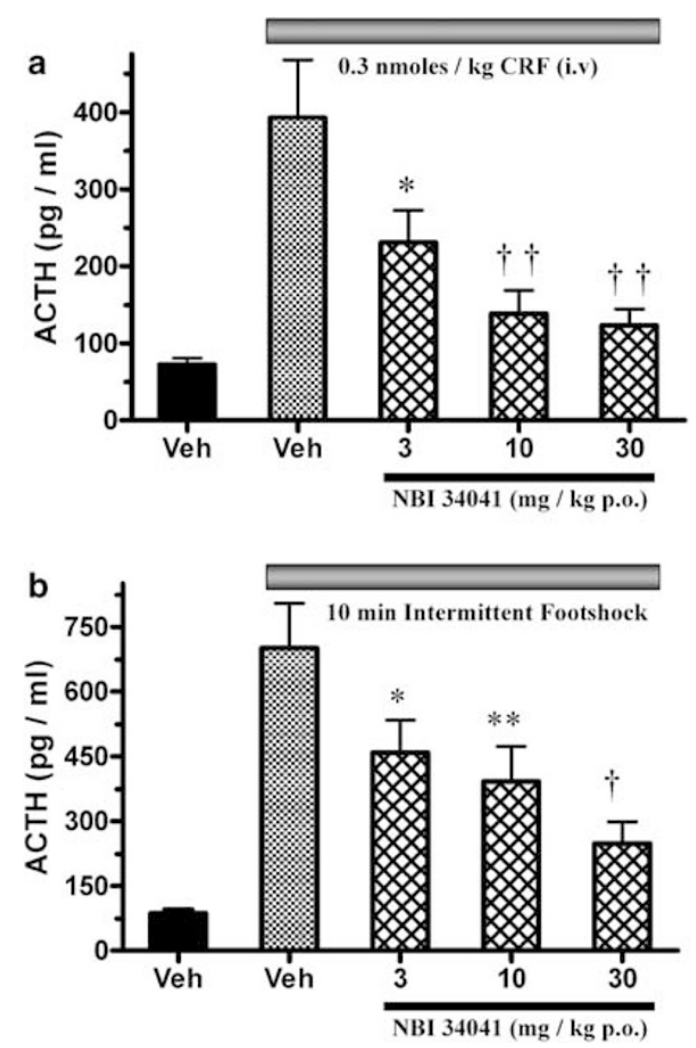

Figure I Inhibition of CRF or stress (intermittent footshock)-induced ACTH release in rats. (a) Dose-dependent effect of NBI-3404I on CRFinduced ACTH release at 10 min following i.v. administration of $0.3 \mathrm{nmol} / \mathrm{kg}$ CRF. This dose of CRF caused a greater than fourfold increase in ACTH levels over basal. (b) Dose-dependent effect of NBI-3404I on intermittent footshock stress-induced ACTH release. Footshock stress increased ACTH release sevenfold over basal vehicle-treated levels. NBI-3404I attenuated both CRF- or stress-induced ACTH release in a dose-dependent manner. * $p<0.05$; $* *$ * $p<0.0$ I; ${ }^{\dagger} p<0.00$ I; ${ }^{\dagger \dagger} p<0.000$ I (significance from CRF- or shock-induced vehicle-treated animals; $n=5-6$ per group).

medication effects, either overall (ACTH: $p=0.421$; cortisol: $p=0.337)$ or with time (ACTH: $p=0.615$; cortisol: $p=0.802)$. We also did not find overall medication effects on 24-h UFC concentration collected on days 1,7 , and 14 $(p=0.436)$ but observed a trend for an interaction between medication and change over time $(p=0.063)$. Simple contrast analysis revealed that the interaction effect can be explained by a pronounced UFC reduction between days 1 and 7 in the $10 \mathrm{mg} /$ day NBI-34041 group that was not found in the two higher dose groups or under placebo $(p=0.043)$. This interaction effect disappears when change in UFC between days 1 and 14 is considered $(p=0.172)$.

CRF stimulation test. CRF stimulation tests were conducted at baseline (day 0) and at day 11. Plasma ACTH and cortisol response following $100 \mu \mathrm{g}$ hCRF were assessed by AUC (trapezoidal) integration. The mean score of the individual 1445 and $1500 \mathrm{~h}$ samples served as baseline (before CRF stimulation).

We found a significant group effect for the ACTH response to the CRF stimulation at day 0 with higher ACTH responses in the $10 \mathrm{mg}$ NBI-34041 group compared 
to the other medication groups $(p=0.040)$. In the second CRF stimulation test after 11 days of treatment, no differences between medication groups were found, neither for the ACTH $(p=0.138)$ nor for the cortisol response $(p=0.570)$ (Figure 2).

Trier social stress test. At day 9, subjects underwent a psychosocial stress test. The medication groups did not differ in the emotional response to the TSST as assessed by the state scale of the STAI (STAI-X1) or in mental arithmetic performance (see Table 2). STAI-X1 scores were on average larger than 45 in all dose groups, which is almost one SD higher than the mean scores of a normative sample (36.69 \pm 12.1 ; Spielberger et al (1996)) suggesting successful
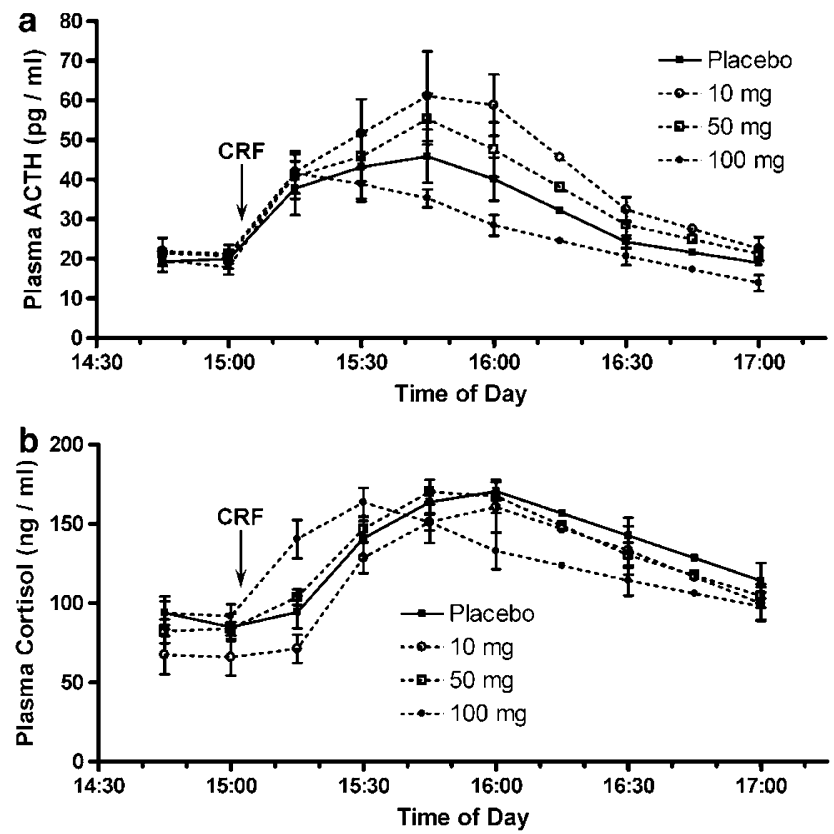

Figure $2 \mathrm{ACTH}$ (a) and cortisol (b) response $(\mu \pm \mathrm{SEM})$ to i.v. stimulation with $100 \mu \mathrm{g}$ human CRF after I I days of treatment (Placebo, - $\mathrm{NBI}-3404 \mathrm{I}, \mathrm{O}-10 \mathrm{mg}, \square-50 \mathrm{mg},-100 \mathrm{mg})$. induction of psychosocial stress to a similar degree in all medication groups.

Neuroendocrine responses to the TSST differed significantly between medication groups. This was evident for the ACTH $(p=0.001)$ as well as for the cortisol response $(p=0.025)$. Post hoc tests revealed a significantly lower cortisol response to psychosocial stress $(p=0.030)$ in the $100 \mathrm{mg} /$ day NBI-34041 group compared to placebo (see Figure 3). The more pronounced medication effect for ACTH is partly attributable to a specifically elevated ACTH response in the $10 \mathrm{mg} /$ day group, a similar effect as already observed in the baseline CRF stimulation test. However, the post hoc test showed a trend suggesting a lower ACTH response $(p=0.074)$ in the $100 \mathrm{mg} /$ day group compared to placebo.

\section{DISCUSSION}

The selective $\mathrm{CRF}_{1}$ receptor antagonist NBI-34041 was assessed both preclinically and in a clinical setting for its ability to reduce stress hormone responses of either exogenously administered CRF or psychosocial stressinduced activation of the HPA axis. NBI-34041 had high affinity and selectivity for the $\mathrm{CRF}_{1}$ receptor in addition to

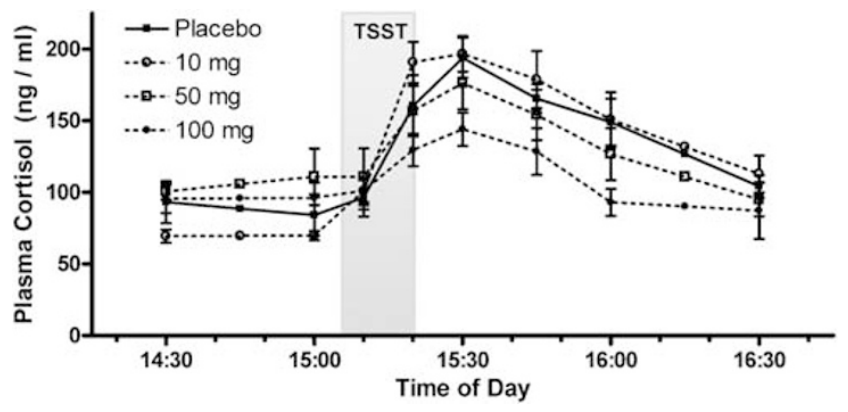

Figure 3 Cortisol response $(\mu \pm \mathrm{SEM})$ to psychosocial stress (TSST administered from 1505-1520 h) on Day 9 of treatment (Placebo, NBI-3404I, O- $10 \mathrm{mg}, \square-50 \mathrm{mg},-100 \mathrm{mg}$ ).

Table 2 Emotional Response (STAI-XI), Mental Arithmetic Results, and Hormone Response ( $\mu \pm$ SD) to Psychosocial Stress (TSST)

\begin{tabular}{|c|c|c|c|c|c|}
\hline & Placebo $(n=6)$ & $10 \mathrm{mg}(n=6)$ & $50 \mathrm{mg}^{\dagger}(n=6)$ & $100 \mathrm{mg}^{\dagger}(\mathrm{n}=6)$ & ANOVA $\left(\mathbf{F}_{3,20}\right)$ \\
\hline Emotional response (STAI-XI) & $45.83 \pm 4.79$ & $55.17 \pm 12.5$ & $54.00 \pm 9.59$ & $50.17 \pm 9.68$ & $p=0.346$ \\
\hline \multicolumn{6}{|l|}{ Mental arithmetic } \\
\hline Number of counts & $43.5 \pm 24.4$ & $45.3 \pm 16.3$ & $34.4 \pm 9.4$ & $55.2 \pm 27.9$ & $p=0.488$ \\
\hline Errors & $3.50 \pm 2.26$ & $4.67 \pm 1.63$ & $2.80 \pm 1.92$ & $3.40 \pm 0.55$ & $p=0.366$ \\
\hline \multicolumn{6}{|l|}{ Hormone response } \\
\hline ACTH (AUC) & $3297 \pm 456$ & $5159 \pm 453$ & $2663 \pm 473$ & $2086 \pm 453$ & $p=0.001^{\ddagger}$ \\
\hline Cortisol (AUC) & $12815 \pm 1849$ & $13492 \pm 2947$ & $1202 \mid \pm 3506$ & $9918 \pm 2097$ & $p=0.025^{\ddagger}$ \\
\hline
\end{tabular}

One subject refused to participate in this task ( $100 \mathrm{mg}$ group) because of fear of failure. Another subject was obviously overstrained by the standard mental arithmetic (50 mg group) and an easier variant was conducted.

${ }^{\ddagger}$ ANCOVA $\left(F_{3,19}\right)$, baseline corrected. 
demonstrating competitive functional antagonism at both the human and rat forms of the receptor confirming that this molecule acts as a neutral antagonist with no intrinsic functional agonist activity; binding, and functional in vitro studies demonstrated that NBI 34041 is completely inactive at the CRF2 receptor (data not shown).

In preclinical in vivo studies, NBI-34041 attenuated the CRF-induced elevation in ACTH in a dose-dependent manner, with a maximum inhibition observed at an intragastric dose of $30 \mathrm{mg} / \mathrm{kg}$. NBI-34041 also produced a significant attenuation of stress (footshock)-induced ACTH release, again with the maximum effect observed at a dose of $30 \mathrm{mg} / \mathrm{kg}$ by oral gavage. These preclinical in vitro and in vivo results indicate that NBI-34041 was effective in reducing endocrine responses to pharmacological and behavioral challenge mediated by $\mathrm{CRF}_{1}$ receptors after enteral administration. To determine human activity, this compound was considered a good candidate for a Phase I clinical study to explore whether the reduction in hormonal and behavioral responses to stress with this compound are also evident in humans.

We compared plasma ACTH, plasma cortisol, and UFC secretion during the study (pharmacodynamic assessments) as well as the plasma ACTH and cortisol responses to a neuroendocrine hCRF and a psychosocial TSST stimulation test in four independent groups of male healthy subjects receiving either placebo or the active compound NBI-34041 in three different doses $(10,50,100 \mathrm{mg} /$ day) for 14 days.

We did not observe significant differences between the four dose groups in diurnal ACTH and cortisol secretion (AUC values between $0800-2000 \mathrm{~h})$ or in UFC $(24 \mathrm{~h}$ secretion). We observed a more pronounced decline in UFC after 7 days in the $10 \mathrm{mg}$ /day dose group but not in the two higher dose groups or under placebo. This effect disappeared after 14 days. An inspection of the individual data suggests that there is no systematic medication effect on UFC concentrations. The UFC decline in the $10 \mathrm{mg} / \mathrm{day}$ group can be attributed to a single outlier, and the effect disappears when this subject is excluded.

Eleven days of treatment with NBI-34041 did not result in significant differences in CRF evoked ACTH and cortisol responses. Even at the highest dose of NBI-34041 the function of the HPA axis remained unimpaired demonstrating that 2 weeks of treatment with NBI-34041 did not affect basal HPA axis function. This is in line with the results of the first clinical trial with NBI 30775, a $\mathrm{CRF}_{1}$ receptor antagonist and predecessor compound of NBI-34041 (Kunzel et al, 2003; Zobel et al, 2000). Importantly however, the results of the TSST after 9 days of treatment indicated that the hormone response to a public speaking and mental arithmetic stressor was attenuated by the $\mathrm{CRF}_{1}$ receptor antagonist, as there was a significant dose group effect for the ACTH and cortisol response. Post hoc tests confirmed significantly lower cortisol response in the $100 \mathrm{mg} / \mathrm{day}$ group compared to placebo. Descriptively, the highest endocrine response to the TSST can be observed in the $10 \mathrm{mg} /$ day group (not significant) and not in the placebo group. Again, individual data inspection suggests that this can be attributed to one single outlier in the $10 \mathrm{mg} / \mathrm{day}$ group who is not identical with the UFC outlier. If this subject is excluded from the analysis, the significant effects of NBI-34041 on the TSST outcome can still be found. No effect on self-reported state anxiety (STAI-X1) was observed. This could be a consequence of the behavioral profile of CRF 1 antagonists that contrasts with those of benzodiazepines and other anxiolytics. Although benzodiazepines exhibit behavioral effects already under low-anxiety baseline conditions, CRF 1 antagonists require a background of high anxiety to exhibit acute anxiolytic effects (Steckler and Dautzenberg, 2006; Zorrilla and Koob, 2004). The group means of the state anxiety scores during the TSST ranged between 45 and 55 (see Table 2), which correspond to moderate anxiety (no anxiety $=20$, high anxiety $=80)$.

From a psychological point of view, moderate tension or vigor during a challenging task like the TSST is an important requirement for achieving optimal performance (Dickman, 2002). Unfortunately, the TSST does not provide standardized performance measure. We have calculated the error rate of the mental arithmetic task (errors per count), the second part of the TSST, and did not find significant group differences, even though the lowest average error rate was observed in the NBI-34041 $100 \mathrm{mg}$ /day group. However, the error rate depends highly on individual skills and cannot be regarded as a reliable performance indicator. Nevertheless, moderate subjective tension in combination with an attenuated stress hormone response should be the optimal prerequisite for mastering stressful challenges.

In order to understand the rationale for antagonizing $\mathrm{CRF}_{1}$ as potential antidepressant treatment we have to discriminate between the neuromodulatory and neuroendocrine function of CRF. Although the neuroendocrine function mediated by $\mathrm{CRF}$ receptors in the anterior pituitary is pivotal for the physiological adaptation to stress, the neuromodulatory function mediated by prefrontal and limbic $\mathrm{CRF}_{1}$ receptors is fundamental for the emotional and behavioral stress response. This could be demonstrated in several animal studies. Central subchronic

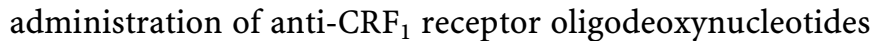
in rats and mice produced anxiolytic effects (Heinrichs et al, 1997; Liebsch et al, 1995, 1999; Skutella et al, 1998) but did not alter plasma ACTH and corticosterone concentrations (Heinrichs et al, 1997; Liebsch et al, 1999). Muller et al (2003) examined anxiety related behavior in conditional $\mathrm{CRF}_{1}$ knockout mice with $\mathrm{CRF}_{1}$ receptor function postnatally inactivated in anterior forebrain and limbic structures but not in the pituitary. Knockout animals exhibited attenuated anxiety-related behavior in different paradigms but no alterations in basal ACTH and corticosterone levels.

These findings suggest that blockade of prefrontal and limbic $\mathrm{CRF}_{1}$ receptors is the primary target of clinically effective $\mathrm{CRF}_{1}$ antagonists. As $\mathrm{CRF}_{1}$ receptors are more abundantly expressed in the anterior pituitary than in the cortex (Hiroi et al, 2001; Sanchez et al, 1999), moderate to high doses of $\mathrm{CRF}_{1}$ antagonists exhibit a sufficient blockade of $\mathrm{CRF}_{1}$ receptors in the prefrontal cortex and the amygdala, but not in the pituitary. This is also supported by the divergent effects of subchronic NBI-34041 treatment in our clinical study; although HPA responsiveness following direct stimulation of the anterior pituitary by exogenous CRF was preserved, the HPA response to psychosocial stressor was attenuated. The higher density of receptors in the anterior pituitary would require higher doses to block exogenously applied CRF because only a fraction of the 
receptors is required for maintaining the maximal responsivity of the pituitary (Aguilera et al, 2004), whereas the applied doses should be sufficient for a blockade of central $\mathrm{CRF}_{1}$ receptors in prefrontal cortex and amygdala, the probable neuroanatomical location of psychosocial stress adaptation.

\section{CONCLUSION}

In summary, we presented preclinical and clinical data indicating that the $\mathrm{CRF}_{1}$ receptor antagonist NBI-34041, can reduce the hormonal response to stress both in animals and humans, although not ablating the CRF elicited stress hormone response. These properties are fundamental for further successful development of drugs designed to treat stress-related disorders. The ideal drug candidate would be one that attenuates the central pathologic increase in CRF activity while preserving the ability of the organism to respond appropriately to stressors with an HPA response. This is the case for NBI-34041, which has been demonstrated in our studies. $\mathrm{CRF}_{1}$ receptor antagonists remain promising candidates for drug development in stressrelated disorders such as depression and anxiety.

\section{ACKNOWLEDGEMENTS}

The work described in this paper was supported by Neurocrine Biosciences Inc., San Diego, CA, USA, and by GlaxoSmithKline, Research Triangle Park, NC, USA. Allan C Foster and Dimitri E Grigoriadis are employees of Neurocrine Biosciences Inc. (NBI). Susan Learned-Coughlin is an employee of GlaxoSmithKline (GSK).

\section{REFERENCES}

Aguilera G, Nikodemova M, Wynn PC, Catt KJ (2004). Corticotropin releasing hormone receptors: two decades later. Peptides 25: 319-329.

Arzt E, Holsboer F (2006). CRF signaling: molecular specificity for drug targeting in the CNS. Trends Pharmacol Sci 27: 531-538.

Britton KT, Lee G, Dana R, Risch SC, Koob GF (1986). Activating and 'anxiogenic' effects of corticotropin releasing factor are not inhibited by blockade of the pituitary-adrenal system with dexamethasone. Life Sci 39: 1281-1286.

Chalmers DT, Lovenberg TW, De Souza EB (1995). Localization of novel corticotropin-releasing factor receptor (CRF2) mRNA expression to specific subcortical nuclei in rat brain: comparison with CRF1 receptor mRNA expression. J Neurosci 15: 6340-6350.

de Kloet ER, Joels M, Holsboer F (2005). Stress and the brain: from adaptation to disease. Nat Rev Neurosci 6: 463-475.

Dickman SJ (2002). Dimensions of arousal: wakefulness and vigor. Hum Factors 44: 429-442.

Gold PW, Chrousos G, Kellner C, Post R, Roy A, Augerinos P et al (1984). Psychiatric implications of basic and clinical studies with corticotropin-releasing factor. Am J Psychiatry 141: 619-627.

Grigoriadis DE (2005). The corticotropin-releasing factor receptor: a novel target for the treatment of depression and anxietyrelated disorders. Expert Opin Ther Targets 9: 651-684.

Grigoriadis DE, Liu XJ, Vaughn J, Palmer SF, True CD, Vale WW et al (1996). 125I-Tyro-sauvagine: a novel high affinity radioligand for the pharmacological and biochemical study of human corticotropin-releasing factor 2 alpha receptors. Mol Pharmacol 50: 679-686.
Gross RS, Guo Z, Dyck B, Coon T, Huang CQ, Lowe RF et al (2005). Design and synthesis of tricyclic corticotropin-releasing factor-1 antagonists. J Med Chem 48: 5780-5793.

Hauger RL, Grigoriadis DE, Dallman MF, Plotsky PM, Vale WW, Dautzenberg FM (2003). International Union of Pharmacology. XXXVI. Current status of the nomenclature for receptors for corticotropin-releasing factor and their ligands. Pharmacol Rev 55: 21-26.

Heinrichs SC, Lapsansky J, Lovenberg TW, De Souza EB, Chalmers DT (1997). Corticotropin-releasing factor CRF1, but not CRF2, receptors mediate anxiogenic-like behavior. Regul Pept 71: 15-21.

Held K, Kunzel H, Ising M, Schmid DA, Zobel A, Murck H et al (2004). Treatment with the CRH1-receptor-antagonist R121919 improves sleep-EEG in patients with depression. J Psychiatr Res 38: $129-136$.

Hiroi N, Wong ML, Licinio J, Park C, Young M, Gold PW et al (2001). Expression of corticotropin releasing hormone receptors type I and type II mRNA in suicide victims and controls. Mol Psychiatry 6: 540-546.

Holsboer F (2003). Corticotropin-releasing hormone modulators and depression. Curr Opin Investig Drugs 4: 46-50.

Holsboer F, Muller OA, Doerr HG, Sippell WG, Stalla GK, Gerken A et al (1984a). ACTH and multisteroid responses to corticotropin-releasing factor in depressive illness: relationship to multisteroid responses after ACTH stimulation and dexamethasone suppression. Psychoneuroendocrinology 9: 147-160.

Holsboer F, von Bardeleben U, Gerken A, Stalla GK, Muller OA (1984b). Blunted corticotropin and normal cortisol response to human corticotropin-releasing factor in depression. $N$ Engl J Med 311: 1127.

Ising M, Kunzel HE, Binder EB, Nickel T, Modell S, Holsboer F (2005). The combined dexamethasone/CRH test as a potential surrogate marker in depression. Prog Neuropsychopharmacol Biol Psychiatry 29: 1085-1093.

Kirschbaum C, Pirke KM, Hellhammer DH (1993). The 'Trier Social Stress Test' - a tool for investigating psychobiological stress responses in a laboratory setting. Neuropsychobiology 28: 76-81.

Kunzel HE, Ising M, Zobel AW, Nickel T, Ackl N, Sonntag A et al (2005). Treatment with a CRH-1-receptor antagonist (R121919) does not affect weight or plasma leptin concentration in patients with major depression. J Psychiatr Res 39: 173-177.

Kunzel HE, Zobel AW, Nickel T, Ackl N, Uhr M, Sonntag A et al (2003). Treatment of depression with the CRH-1-receptor antagonist R121919: endocrine changes and side effects. J Psychiatr Res 37: 525-533.

Laux L, Glanzmann P, Schaffner P, Spielberger CD (1981). The State-Trait Anxiety Inventory (STAI). Beltz: Weinheim, Germany.

Liebsch G, Landgraf R, Engelmann M, Lorscher P, Holsboer F (1999). Differential behavioural effects of chronic infusion of CRH 1 and CRH 2 receptor antisense oligonucleotides into the rat brain. J Psychiatr Res 33: 153-163.

Liebsch G, Landgraf R, Gerstberger R, Probst JC, Wotjak CT, Engelmann $\mathrm{M}$ et al (1995). Chronic infusion of a CRH1 receptor antisense oligodeoxynucleotide into the central nucleus of the amygdala reduced anxiety-related behavior in socially defeated rats. Regul Pept 59: 229-239.

McCarthy JR, Heinrichs SC, Grigoriadis DE (1999). Recent progress in corticotropin-releasing factor receptor agents. In: Robertson DW (ed). Annual Reports in Medicinal Chemistry. Academic Press: San Diego, CA. pp 11-20.

Merali Z, Du L, Hrdina P, Palkovits M, Faludi G, Poulter MO et al (2004). Dysregulation in the suicide brain: mRNA expression of corticotropin-releasing hormone receptors and $\mathrm{GABA}(\mathrm{A})$ receptor subunits in frontal cortical brain region. J Neurosci 24: 1478-1485. 
Muller MB, Zimmermann S, Sillaber I, Hagemeyer TP, Deussing JM, Timpl P et al (2003). Limbic corticotropin-releasing hormone receptor 1 mediates anxiety-related behavior and hormonal adaptation to stress. Nat Neurosci 6: 1100-1107.

Nemeroff CB, Bissette G, Akil H, Fink M (1991). Neuropeptide concentrations in the cerebrospinal fluid of depressed patients treated with electroconvulsive therapy. Corticotrophin-releasing factor, beta-endorphin and somatostatin. $\mathrm{Br} J$ Psychiatry 158: 59-63.

Nemeroff CB, Owens MJ, Bissette G, Andorn AC, Stanley M (1988). Reduced corticotropin releasing factor binding sites in the frontal cortex of suicide victims. Arch Gen Psychiatry 45: 577-579.

Nemeroff CB, Widerlov E, Bissette G, Walleus H, Karlsson I, Eklund $\mathrm{K}$ et al (1984). Elevated concentrations of CSF corticotropin-releasing factor-like immunoreactivity in depressed patients. Science 226: 1342-1344.

Pepin MC, Pothier F, Barden N (1992). Impaired type II glucocorticoid-receptor function in mice bearing antisense RNA transgene. Nature 355: 725-728.

Perrin MH, Vale WW (1999). Corticotropin releasing factor receptors and their ligand family. Ann NY Acad Sci 885: 312-328.

Rossier J, French ED, Rivier C, Ling N, Guillemin R, Bloom FE (1977). Foot-shock induced stress increases beta-endorphin levels in blood but not brain. Nature 270: 618-620.

Roy A, Pickar D, Paul S, Doran A, Chrousos GP, Gold PW (1987). CSF corticotropin-releasing hormone in depressed patients and normal control subjects. Am J Psychiatry 144: 641-645.

Ruch W (1999). The revised version of the Eysenck Personality Questionnaire and the development of the German version of the EPQ-R and EPQ-RK. Zeitschrift für Differentielle und Diagnostische Psychologie 20: 1-24.

Sanchez MM, Young LJ, Plotsky PM, Insel TR (1999). Autoradiographic and in situ hybridization localization of corticotropin- releasing factor 1 and 2 receptors in nonhuman primate brain. J Comp Neurol 408: 365-377.

Saunders J, Williams J (2003). Antagonists of the corticotropin releasing factor receptor. Prog Med Chem 41: 195-247.

Skelton KH, Owens MJ, Nemeroff CB (2000). The neurobiology of urocortin. Regul Pept 93: 85-92.

Skutella T, Probst JC, Renner U, Holsboer F, Behl C (1998). Corticotropin-releasing hormone receptor (type I) antisense targeting reduces anxiety. Neuroscience 85: 795-805.

Spielberger CD, Gorsuch RL, Lushene RE (1996). State-TraitAnxiety Inventory Selfrating scale. In: Collegium Internationale Psychiatriae Scalarum (CIPS) (ed). Internationale Skalen für Psychiatrie. Beltz: Göttingen, Germany. pp 27-30.

Steckler T, Dautzenberg FM (2006). Corticotropin-releasing factor receptor antagonists in affective disorders and drug dependence-an update. CNS Neurol Disord Drug Targets 5: 147-165.

Strohle A, Poettig M, Barden N, Holsboer F, Montkowski A (1998). Age- and stimulus-dependent changes in anxiety-related behaviour of transgenic mice with GR dysfunction. Neuroreport 9: 2099-2102.

Wittchen HU, Zaudig M, Fydrich T (1997). SCID. Structured Clinical Interview for DSM-IV. Hogrefe: Göttingen, Germany.

Zimmermann U, Spring K, Kunz-Ebrecht SR, Uhr M, Wittchen HU, Holsboer F (2004). Effect of ethanol on hypothalamicpituitary-adrenal system response to psychosocial stress in sons of alcohol-dependent fathers. Neuropsychopharmacology 29: 1156-1165.

Zobel AW, Nickel T, Kunzel HE, Ackl N, Sonntag A, Ising M et al (2000). Effects of the high-affinity corticotropin-releasing hormone receptor 1 antagonist R121919 in major depression: the first 20 patients treated. J Psychiatr Res 34: 171-181.

Zorrilla EP, Koob GF (2004). The therapeutic potential of CRF1 antagonists for anxiety. Expert Opin Investig Drugs 13: 799-828. 